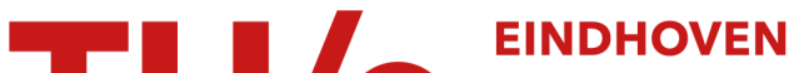 \\ UNIVERSITY OF \\ TECHNOLOGY
}

\section{Structure sensitivity of silver-catalyzed ethylene epoxidation}

\section{Citation for published version (APA):}

van Hoof, A., Hermans, E. A. R., van Bavel, A. P., Friedrich, H., \& Hensen, E. J. M. (2019). Structure sensitivity of silver-catalyzed ethylene epoxidation. ACS Catalysis, 9(11), 9829-9839.

https://doi.org/10.1021/acscatal.9b02720

DOI:

10.1021/acscatal.9b02720

Document status and date:

Published: 19/09/2019

\section{Document Version:}

Publisher's PDF, also known as Version of Record (includes final page, issue and volume numbers)

\section{Please check the document version of this publication:}

- A submitted manuscript is the version of the article upon submission and before peer-review. There can be important differences between the submitted version and the official published version of record. People interested in the research are advised to contact the author for the final version of the publication, or visit the $\mathrm{DOI}$ to the publisher's website.

- The final author version and the galley proof are versions of the publication after peer review.

- The final published version features the final layout of the paper including the volume, issue and page numbers.

Link to publication

\section{General rights}

Copyright and moral rights for the publications made accessible in the public portal are retained by the authors and/or other copyright owners and it is a condition of accessing publications that users recognise and abide by the legal requirements associated with these rights.

- Users may download and print one copy of any publication from the public portal for the purpose of private study or research.

- You may not further distribute the material or use it for any profit-making activity or commercial gain

- You may freely distribute the URL identifying the publication in the public portal.

If the publication is distributed under the terms of Article 25fa of the Dutch Copyright Act, indicated by the "Taverne" license above, please follow below link for the End User Agreement:

www.tue.nl/taverne

Take down policy

If you believe that this document breaches copyright please contact us at:

openaccess@tue.nl

providing details and we will investigate your claim. 


\title{
Structure Sensitivity of Silver-Catalyzed Ethylene Epoxidation
}

\author{
A. J. F. van Hoof, ${ }^{\dagger}$ E. A. R. Hermans, ${ }^{\dagger}$ A. P. van Bavel, ${ }^{\ddagger}$ H. Friedrich, ${ }^{\S}{ }^{\circledR}$ and E. J. M. Hensen ${ }^{*}{ }^{\dagger}(0)$ \\ ${ }^{\dagger}$ Laboratory of Inorganic Materials and Catalysis, Department of Chemical Engineering and Chemistry, Eindhoven University of \\ Technology, Den Dolech 2, 5600 MB Eindhoven, The Netherlands \\ ${ }^{\sharp}$ Shell Global Solutions International B.V., P.O. Box 38000, 1030 BN Amsterdam, The Netherlands \\ ${ }^{\S}$ Laboratory of Materials and Interface Chemistry, Department of Chemical Engineering and Chemistry, Eindhoven University of \\ Technology, Den Dolech 2, 5600 MB Eindhoven, The Netherlands
}

\section{Supporting Information}

ABSTRACT: The influence of particle size $(20-200 \mathrm{~nm})$ of $\mathrm{Ag} / \alpha-\mathrm{Al}_{2} \mathrm{O}_{3}$ catalysts for epoxidation of ethylene to ethylene oxide (EO) under industrial conditions was investigated. Small silver particles up to $\sim 40 \mathrm{~nm}$ are predominantly monocrystalline and show a decreasing weight-normalized reaction rate with increasing particle size. Particles larger than $50 \mathrm{~nm}$ consist of multiple silver crystallites with a much smaller domain size between 25 and $30 \mathrm{~nm}$. For these polycrystalline silver particles, the weight-normalized reaction rate is independent of particle size. The ethylene conversion rate normalized to the external surface area increases when the silver particles become larger. We attribute this to a specific role of the grain boundaries between silver crystallites in supplying oxygen
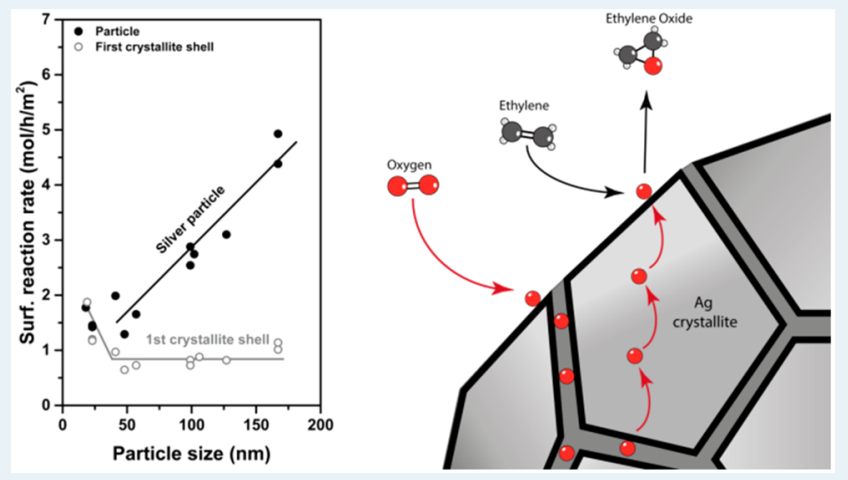
atoms to the external surface. Oxygen is likely activated at defects of an otherwise low-reactivity silver surface (for oxygen adsorption) followed by diffusion along grain boundaries, dissolution in the bulk, and diffusion to the external surface, where oxygen atoms react with ethylene. The reaction rate normalized to the surface area of the first outer shell of crystallites making up silver particles is independent of size for polycrystalline particles. A higher reaction pressure benefits ethylene oxidation rate and EO selectivity due to a higher oxygen coverage. Adding chlorine further improves the EO selectivity through modification of the active surface. The same particle size dependences are observed at 1 bar and at 20 bar without and with chlorine. The main finding of our work is that for large enough particles the ethylene oxidation rate normalized to the silver weight is independent of size. In addition to the size-independent weight-based activity, the preference for larger particles in industrial catalysts can be attributed to the high silver loadings used to obtain larger silver particles. The resulting high coverage of the $\alpha$ $\mathrm{Al}_{2} \mathrm{O}_{3}$ support with silver decreases undesired consecutive reactions of $\mathrm{EO}$ on its hydroxyl groups.

KEYWORDS: ethylene epoxidation, silver, particle size, chlorine, support

\section{INTRODUCTION}

With an annual production of 35 million tons, the direct epoxidation of ethylene to ethylene oxide (EO) constitutes one of the major heterogeneous catalytic processes in the chemical industry. ${ }^{1}$ EO is primarily used as an intermediate in the production of other useful chemicals. The most important derivative is ethylene glycol, which is used for the manufacture of polyester fibers and for antifreeze purposes. ${ }^{2}$ One of the main applications is in the production of polyethylene terephthalate for packing films and bottles.

The heart of the ethylene oxide process is the unique ability of silver to catalyze the selective addition of an oxygen atom from $\mathrm{O}_{2}$ across the carbon-carbon double bond in ethylene. ${ }^{3}$ Using appropriate promoters such as cesium and chlorine, the EO selectivity can exceed $80 \%$ under industrial conditions. ${ }^{2,4}$ The high selectivity is thought to derive from the electrophilic nature of particular surface oxygen species, whose properties are modified by subsurface oxygen. The electrophilicity can also be enhanced by the use of chlorine as a promoter for the selectivity. ${ }^{5}$ Nucleophilic oxygen species, on the other hand, may give rise to the unselective combustion of ethylene, in which acetaldehyde features as an intermediate. ${ }^{6-8}$ Generally, it is believed that the silver surface remains metallic and contains different types of atomic oxygen species under the reaction conditions. ' Moreover, the silver can reconstruct under the influence of oxygen coverage. The epoxidation is thought to occur via an oxametallacycle intermediate, which can be converted to the desired EO product or acetaldehyde, which is rapidly combusted on silver. ${ }^{10,11}$ Another unselective route is isomerization of $\mathrm{EO}$ to acetaldehyde on acidic groups of the support.

Received: June 28, 2019

Revised: September 17, 2019

Published: September 19, 2019 
As is commonly observed in heterogeneous nanoparticle catalysis, the performance in terms of activity and selectivity of silver nanoparticles in ethylene epoxidation is strongly affected by their size. The structure sensitivity of metal nanoparticles for reactions such as ammonia synthesis, carbon monoxide hydrogenation, and methane steam reforming is currently well understood in terms of specific topological arrangements of surface metal atoms that appear for particles smaller than 10 nm. ${ }^{3-6}$ Very different from this, optimum silver particles for EO formation are much larger than $10 \mathrm{~nm}$, typically in the range of $100-1000 \mathrm{~nm}^{2}$ As stated by Goncharova et al., this is somewhat surprising, as we may expect particles larger than 10 $\mathrm{nm}$ to behave as bulk silver. ${ }^{7}$ Accordingly, the size effect for silver-catalyzed ethylene oxidation has been investigated by many authors.

The first important reports on the effect of silver particle size on ethylene epoxidation were published in the 1970s by $\mathrm{Wu}$ and Harriot and in the 1980 s by Verykios et al. ${ }^{8,9}$ A decrease in the catalytic activity upon a particle size increase from 5 to 60$70 \mathrm{~nm}$ followed by an increasing activity for larger particles was mentioned in these works. Later on, Lee et al. published seemingly opposing results, by showing an increasing activity from 20 to $40 \mathrm{~nm}$ followed by a decrease for larger particles in the $60-100 \mathrm{~nm}$ range. ${ }^{10}$ Such a variation of reported particle size dependences is also evident from other work. ${ }^{11-13}$ It has been speculated that under the reaction conditions smaller particles contain less electrophilic oxygen species, which are crucial for selective ethylene conversion to EO. ${ }^{12}$ Gonchorova et al., on the other hand, mentioned that the surfacenormalized ethylene oxidation rate correlates with the number of crystallites per silver particle. ${ }^{7,14}$ Accordingly, these authors proposed that the grain boundaries in silver particles play an important role. Most of these studies were performed under conditions far from industrial practice. Only a few investigations studied the influence of elevated pressure, and only one involved the use of an industrial cesium promoter. ${ }^{13}$ To the best of our knowledge, no literature has discussed the structure sensitivity of silver particle catalysts in the presence of the common industrial chlorine promoter under high pressure. Although an important corollary of the previous works is that high EO selectivity is related to large silver particles, a recent study claimed that this is merely due to differences in ethylene conversion. $^{20}$ In summary, despite efforts to explore the structure sensitivity of silver catalysts, there is no consensus on how the size of silver particles affects their performance in ethylene epoxidation.

In the present work, we systematically investigated how the ethylene conversion rate depends on the silver particle size under close to industrial conditions. Silver catalysts were synthesized by impregnation of a silver oxalate precursor on an $\alpha-\mathrm{Al}_{2} \mathrm{O}_{3}$ support with a relatively low surface area in the presence of ethylenediamine. ${ }^{15}$ Average particle sizes between 19 and $183 \mathrm{~nm}$ were obtained by adjusting the silver loading and the gas composition and temperature used to decompose the precursor. The catalysts were characterized by physicochemical techniques, including elemental analysis, XRD, SEM, HAADF-STEM, and $\mathrm{O}_{2}$-TPD. Catalytic performance was determined under total pressures of 1 and 20 bar. The influence of the chlorine promoter (added in the form of vinyl chloride) was determined under a pressure of 20 bar. In our discussion, we emphasize the influence of silver particle size on the ethylene oxidation rate in which the polycrystalline nature of larger silver particles is shown to play an important role.

\section{EXPERIMENTAL METHODS}

Catalyst Preparation. As-received $3 \mathrm{~mm} \alpha-\mathrm{Al}_{2} \mathrm{O}_{3}$ pellets (Saint-Gobain NorPro, SA 5102) were crushed and sieved to obtain a $125-250 \mu \mathrm{m}$ size fraction followed by calcination overnight at $550{ }^{\circ} \mathrm{C}$. Silver oxalate $\left(\mathrm{Ag}_{2} \mathrm{C}_{2} \mathrm{O}_{4}\right)$ was prepared by dissolving silver nitrate $\left(\mathrm{AgNO}_{3}\right.$, Alfa Aesar, ACS, $\geq 99.9 \%, 5$ g) and oxalic acid $\left(\mathrm{C}_{2} \mathrm{H}_{2} \mathrm{O}_{4}\right.$, Sigma-Aldrich, ReagentPlus, $\geq 99 \%, 50 \mathrm{~g}$ ) in $100 \mathrm{~mL}$ of deionized water followed by stirring for $10 \mathrm{~min}$. The obtained white suspension was filtered and washed with deionized water three times. Afterward, the solid was dried under vacuum overnight and stored until further use.

Supported silver catalysts were prepared according to a known procedure for obtaining industrial EO catalysts. ${ }^{15}$ To this end, the sieved $\alpha$-alumina support was impregnated by a silver oxalate/ethylenediamine (molar ratio 1/3) solution in deionized water. The total amount of silver oxalate was adjusted to obtain silver loadings between 2 and $10 \mathrm{wt} \%$. The impregnated catalyst precursor was vacuum-dried at room temperature for $1 \mathrm{~h}$ and calcined in a flow of 0 or $10 \mathrm{vol} \%$ oxygen in helium at 1 atm and 275,400 , or $500{ }^{\circ} \mathrm{C}$ using a heating rate of $10{ }^{\circ} \mathrm{C} \mathrm{min}{ }^{-1}$ and an isothermal dwell of $4 \mathrm{~h}$.

Characterization. The silver content of the samples was determined by inductively coupled plasma (ICP) analysis performed on a Spectroblue spectrometer with optical emission spectroscopy (OES) and a CETAC ASX-520 Auto Sampler. For analysis, $25-50 \mathrm{mg}$ of the sample was mixed with $20 \mathrm{~mL}$ of a $3 \mathrm{M} \mathrm{HNO}_{3}$ solution. The dispersion was stirred and heated to $80{ }^{\circ} \mathrm{C}$ for $1 \mathrm{~h}$ to extract all of the silver from the support material. The solution was then cooled to room temperature and diluted to $50 \mathrm{~mL}$ in a volumetric flask. The alumina residue was allowed to settle down, and then $5 \mathrm{~mL}$ of this solution was taken in another volumetric flask and diluted to $50 \mathrm{~mL}$. Around $25 \mathrm{~mL}$ of this diluted solution was used for analysis. All ICP-OES measurements were carried out in duplicate.

The phase composition of the samples was determined by Xray diffraction (XRD), recorded with a Bruker D2 Endeavor powder diffraction system using $\mathrm{Cu} \mathrm{K} \alpha$ radiation. The XRD patterns were recorded in air. The scanning speed was $6.0^{\circ} 2 \theta$ $\mathrm{min}^{-1}$ in the range of $5-90^{\circ} 2 \theta$. Crystallite sizes were determined by applying the Scherrer equation to the (220) reflection of the silver phase, using $d_{\text {crystallite }}=\frac{K \lambda}{\beta \cos \theta}$ with $K$ being the shape factor (0.9), $\lambda$ the X-ray wavelength, and $\beta$ and $\theta$ the full-width at half-maximum and the Bragg angle of the (220) reflection, respectively. In situ XRD patterns were recorded on a Bruker D8 Advance instrument, which was equipped with an environmental cell, using $\mathrm{Cu} \mathrm{K} \alpha$ radiation.

High-angle annular dark field scanning transmission electron microscopy (HAADF-STEM) was performed on a TU/e CryoTitan instrument (FEI, now Thermo Fischer-Scientific) at room temperature. (S)TEM sample preparation involved sonication of the samples in pure ethanol (Biosolve, extra dry, $99.9 \%$ ) and application of a few droplets of the suspension to a 200 mesh Cu TEM grid with a holey carbon support film. Prior to imaging, the supported samples were left in an oven at $40{ }^{\circ} \mathrm{C}$ overnight to remove residual ethanol. STEM images were acquired using a probe convergence angle of $10 \mathrm{mrad}$, a dwell time of $2 \mu \mathrm{s}$, and a camera length of $89 \mathrm{~mm}$ in combination with a Fischione HAADF detector. Scanning electron microscopy (SEM) images were taken by a FEI Quanta 200F scanning electron microscope at an accelerating voltage of $3 \mathrm{kV}$ and spot size 4.5 . 
Table 1. Parameters Used To Control Particle Size for $\mathrm{Ag} / \alpha-\mathrm{Al}_{2} \mathrm{O}_{3}$ Catalysts

\begin{tabular}{|c|c|c|c|c|c|c|c|c|}
\hline sample name & $\mathrm{He} / \mathrm{O}_{2}(\operatorname{vol} \%)$ & $T\left({ }^{\circ} \mathrm{C}\right)$ & $\operatorname{Ag}(\text { wt } \%)^{a}$ & particle size $(\mathrm{nm})^{b}$ & $\sigma(\mathrm{nm})^{b}$ & $n^{b}$ & $\mathrm{SE}(\mathrm{nm})^{b}$ & $\operatorname{XRD}(\mathrm{nm})^{c}$ \\
\hline $\operatorname{Ag}(19)$ & $100 / 0$ & 400 & 1.3 & 19 & 9 & 200 & 0.64 & 19 \\
\hline $\operatorname{Ag}(23)$ & $100 / 0$ & 275 & 1.7 & 23 & 11 & 400 & 0.55 & 19 \\
\hline $\operatorname{Ag}(41)$ & $100 / 0$ & 275 & 4.5 & 41 & 16 & 400 & 0.80 & 20 \\
\hline $\operatorname{Ag}(48)$ & $90 / 10$ & 275 & 1.7 & 48 & 19 & 400 & 0.95 & 24 \\
\hline $\operatorname{Ag}(57)$ & $90 / 10$ & 275 & 4.0 & 57 & 21 & 400 & 1.05 & 25 \\
\hline $\operatorname{Ag}(99)$ & $90 / 10$ & 275 & 8.7 & 99 & 32 & 400 & 1.60 & 26 \\
\hline $\operatorname{Ag}(106)$ & $90 / 10$ & 275 & 8.2 & 106 & 47 & 199 & 3.33 & 30 \\
\hline $\operatorname{Ag}(127)$ & $90 / 10$ & 275 & 10.0 & 127 & 47 & 349 & 2.53 & 27 \\
\hline $\operatorname{Ag}(167)$ & $90 / 10$ & 500 & 7.8 & 167 & 58 & 291 & 3.42 & 26 \\
\hline $\operatorname{Ag}(183)$ & $90 / 10$ & 275 & 14.4 & 183 & 89 & 484 & 4.05 & 28 \\
\hline
\end{tabular}

${ }^{a}$ Weight loading determined by ICP-OES. ${ }^{b}$ Particle size determined by HAADF-STEM ( $\sigma$ standard deviation, $n$ number of paricles, SE standard error of mean $\sigma / \sqrt{ } n)$. ${ }^{c}$ Determined by applying the Scherrer equation on the $\operatorname{Ag}(220)$ XRD peak.

(a)

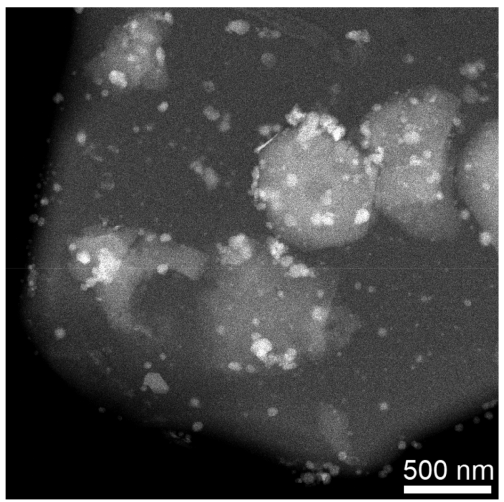

(b)

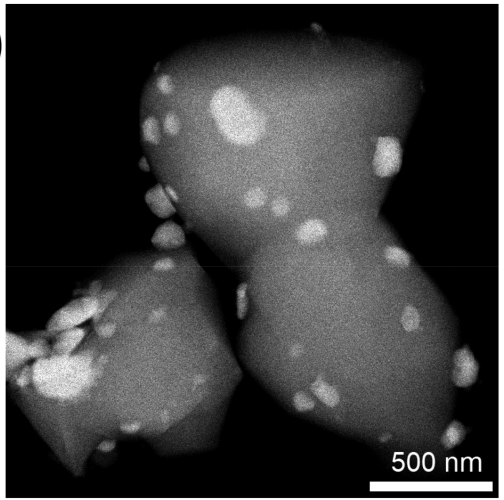

(c)

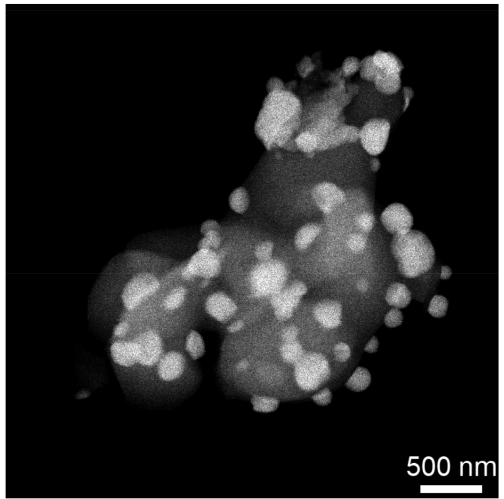

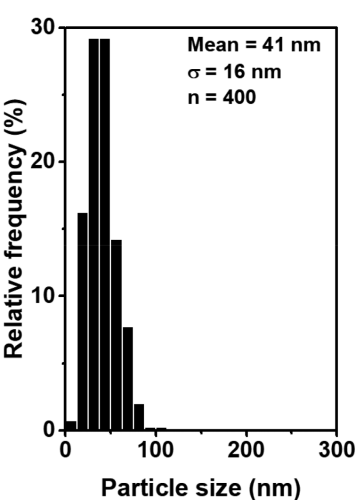
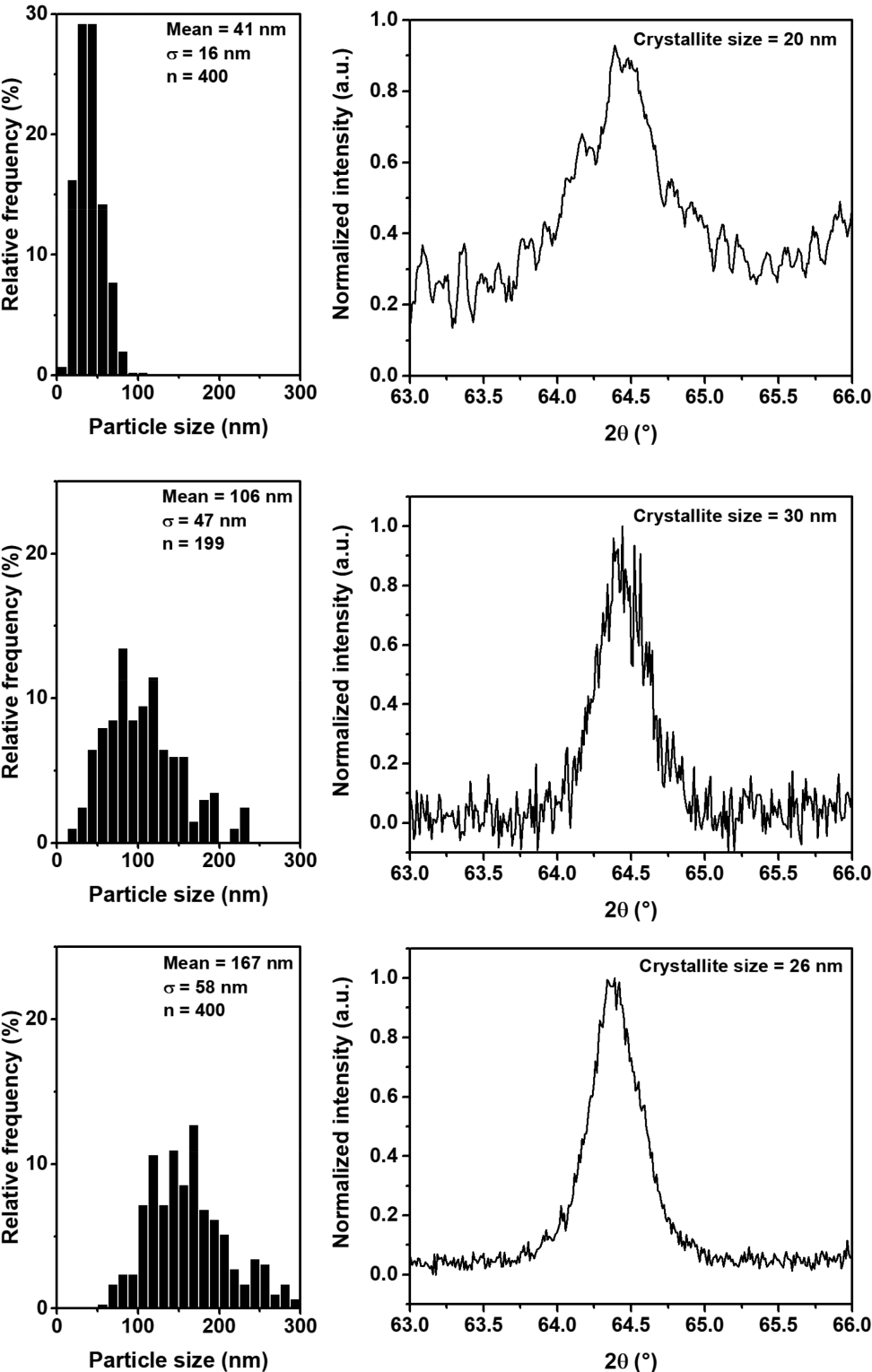

Figure 1. HAADF-STEM images, corresponding histograms, and magnification of the XRD diffractogram of the $\mathrm{Ag}(220)$ region for the selected catalysts (a) $\mathrm{Ag}(41),(\mathrm{b}) \mathrm{Ag}(106)$, and (c) $\mathrm{Ag}(167)$. The diffractogram of $\mathrm{Ag}(41)$ was smoothed with a five-point moving average.

XPS measurements were carried out with a Thermo Scientific K-Alpha apparatus, equipped with a monochromatic small-spot X-ray source and a $180^{\circ}$ double-focusing hemi- spherical analyzer with a 128-channel detector. Spectra were obtained using an aluminum anode ( $\mathrm{Al} \mathrm{K} \alpha=1486.6 \mathrm{eV}$ ) operating at $72 \mathrm{~W}$ and a spot size of $400 \mu \mathrm{m}$. Survey scans 

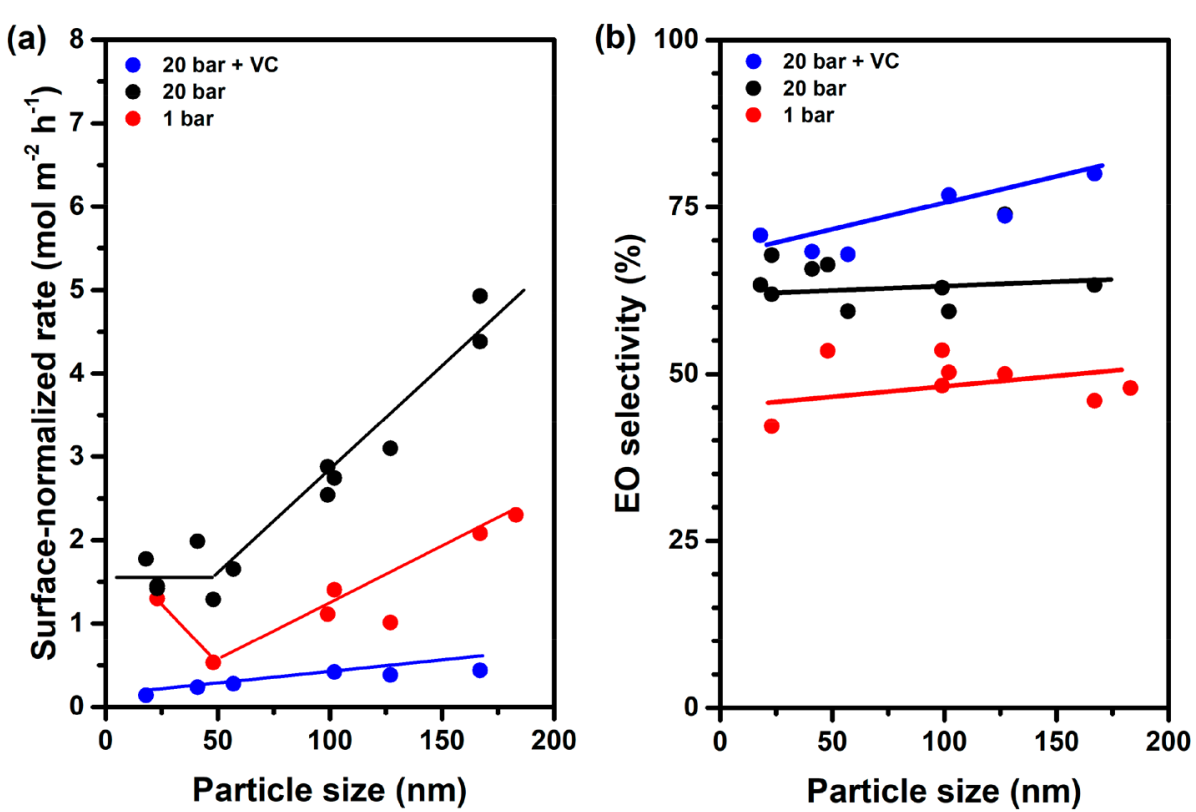

Figure 2. (a) Surface-normalized ethylene oxidation rate as a function of the silver particle size. Steady-state reaction rates are normalized to the number-weighted average particle size of the fresh catalyst (number-, area-, and volume-averaged particle size dependence in Figure S5). (b) EO selectivity as a function of silver particle size (reaction conditions: $225^{\circ} \mathrm{C}, 5 \% \mathrm{C}_{2} \mathrm{H}_{4}, 10 \% \mathrm{O}_{2}$, further conditions in the figure). Lines are added to guide the eye.

were measured at a constant pass energy of $200 \mathrm{eV}$ and region scans at $50 \mathrm{eV}$. The background pressure was $2 \times 10^{-9} \mathrm{mbar}$ and during measurement was $3 \times 10^{-7}$ mbar argon because of the charge compensation dual-beam source. XPS spectra were fitted with CasaXPS. A Shirley background subtraction was applied, and Gauss-Lorentz curves were fitted (Supporting Information, Figure S1).

$\mathrm{O}_{2}$-TPD (temperature-programmed desorption) experiments were carried out in a plug flow quartz reactor. A 250 $\mathrm{mg}$ amount of the as-prepared catalyst was loaded in the reactor and heated $\left(225^{\circ} \mathrm{C}, 20^{\circ} \mathrm{C} \mathrm{min}{ }^{-1}\right)$ in an oxygen flow $\left(10 \mathrm{~mL} \mathrm{~min}{ }^{-1}\right)$ for $3 \mathrm{~h}$ at atmospheric pressure followed by cooling to $50{ }^{\circ} \mathrm{C}$. Then, the oxygen flow was replaced by a helium flow for $0.5 \mathrm{~h}$, followed by heating in a He flow to 550 ${ }^{\circ} \mathrm{C}$ at a rate of $10{ }^{\circ} \mathrm{C} \mathrm{min}^{-1}$. Gas analysis was performed by the mass spectrometer (quadrupole mass spectrometer, Balzers TPG 251). The monitored gases were hydrogen $(\mathrm{m} / z 2)$, helium $(m / z 4)$, methane $(m / z 16)$, water $(m / z 18)$, nitrogen $(m / z 28)$, oxygen $(m / z 32)$, and carbon dioxide $(m / z 44)$. The current intensity was measured against time and normalized by the helium signal.

Catalytic Activity Measurements. The catalytic activity measurements were performed in a continuous plug-flow reactor. The stainless-steel reactor was loaded with $20-150 \mathrm{mg}$ of silver catalyst, maintained between quartz plugs. The catalyst loading was adjusted to achieve an ethylene conversion below $10 \%$. The pretreatment gas mixture consisted of $10 \mathrm{vol}$ $\%$ oxygen in helium, and a total flow of $20 \mathrm{~mL} \mathrm{~min}^{-1}$ was maintained by thermal mass flow controllers. Before reaction, the pretreatment gas flow through the reactor was stabilized at the reaction pressure (typically $20 \mathrm{bar}$ ) for $2 \mathrm{~h}$. Then, the reactor was heated to $225{ }^{\circ} \mathrm{C}$ at a rate of $20{ }^{\circ} \mathrm{C} \mathrm{min}{ }^{-1}$ and dwelled for $3 \mathrm{~h}$ in the pretreatment gas. The reaction was started by switching two fast four-way valves which replaced the pretreatment gas by the reaction feed mixture. The reaction feed mixture consisted of 10 vol \% oxygen and 5 vol \% ethylene balanced by helium, at a total flow of $20 \mathrm{~mL} \mathrm{~min}^{-1}$.
Optionally, a small flow of a mixture of 99.5 ppm vinyl chloride (VC) in helium was added to achieve a final chloride concentration of $1 \mathrm{ppm}$. Online gas analysis was carried out by a three-channel gas chromatograph (Compact GC, Interscience) equipped with one flame ionization detector (FID) and two thermal conductivity detectors (TCD). The FID coupled with an Rt-QSBond column was used to analyze ethylene oxide and acetaldehyde. One TCD coupled with a Molsieve 5A column was used to analyze oxygen. The second TCD coupled with an Rt-QBond column was used to detect carbon dioxide and ethylene. The main products were analyzed at intervals of $5 \mathrm{~min}$. After $2-60 \mathrm{~h}$, the reaction was stopped by replacing the feed mixture by helium and cooling the reactor to room temperature.

\section{RESULTS AND DISCUSSION}

The silver catalysts were prepared according to a (patent) literature procedure in which the $\alpha-\mathrm{Al}_{2} \mathrm{O}_{3}$ support (surface area $1.04 \mathrm{~m}^{2} \mathrm{~g}^{-1}$ ) was impregnated with an aqueous solution containing silver oxalate and ethylenediamine. ${ }^{15,16}$ After drying, the catalyst precursor was heated under an oxygenhelium atmosphere to remove the organic ligands. To control the silver particle size, the silver loading, the oxygen partial pressure, and the temperature of calcination were varied. Table 1 gives the main properties of the prepared catalysts in this study. XPS showed that there was no nitrogen left from the ethylenediamine ligand used in the preparation after calcination (Figure S1). We employed HAADF-STEM to determine the size and size distribution of the silver particles. Representative HAADF-STEM images and corresponding histograms of the catalysts are shown in Figure 1. Corresponding particle size histograms of the other catalysts are included in Figure S2. The average particle size in the silver catalysts ranged from 19 to $183 \mathrm{~nm}$. Analysis of the particle size using SEM confirmed these results (Figure S3). The Ag/ $\mathrm{Al}$ ratio obtained by XPS correlated well with the product of the surface area determined from the average silver particle size 

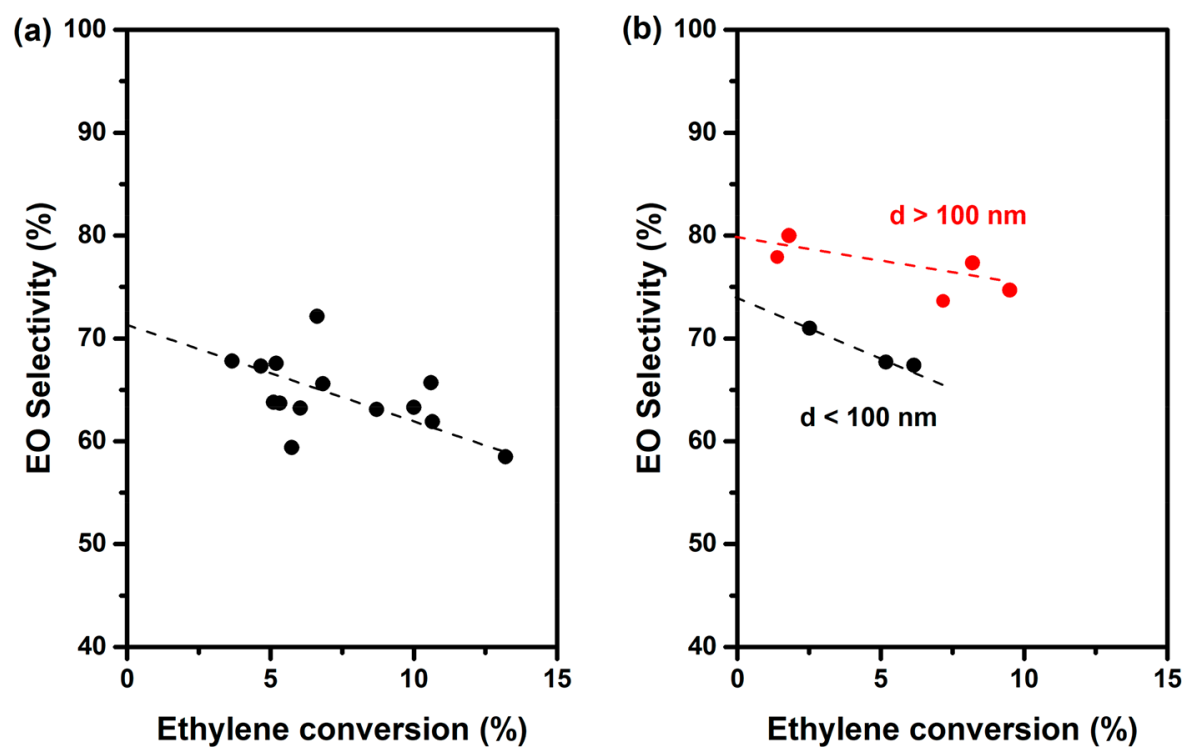

Figure 3. EO selectivity as a function of ethylene conversion (reaction conditions: $225{ }^{\circ} \mathrm{C}, 5 \% \mathrm{C}_{2} \mathrm{H}_{4}, 10 \% \mathrm{O}_{2}$ ): (a) 1 and 20 bar; (b) 20 bar $+\mathrm{VC}$. Lines are guide to the eye, and dashed lines extrapolate EO selectivity to zero ethylene conversion.

and weight loading (Figure S4). The silver crystallite size was determined by analysis of the broadening of the (220) reflection of silver in the XRD patterns. ${ }^{17}$ We used the fwhm method and established that the use of the integral breadth method gave very similar results. Some representative diffractograms in the $\operatorname{Ag}(220)$ region are shown in Figure 1. The primary crystallite size of the silver particles in our samples varied between 19 and $30 \mathrm{~nm}$. Using the same method, the crystallite size of a micrometer-sized silver powder was determined to be $\sim 50 \mathrm{~nm}$.

The catalytic performance of the silver samples was evaluated in the selective oxidation of ethylene at a temperature of $225{ }^{\circ} \mathrm{C} .{ }^{2,15,18}$ In all cases, the reaction feed consisted of $5 \%$ ethylene and $10 \%$ oxygen balanced by helium. Reactions were carried out under three different conditions: (A) at a pressure of 20 bar in the presence of $1 \mathrm{ppm} \mathrm{VC,} \mathrm{(B)} \mathrm{at}$ a pressure of 20 bar without $\mathrm{VC}$, and (C) at a pressure of 1 bar without VC. The experiments carried out in the presence of chlorine at a pressure of 20 bar (conditions A) are closest to those employed in industrial EO production. We observed substantial changes in the ethylene conversion and EO selectivity as a function of the time on stream, especially in the presence of VC. These aspects will be discussed later, after comparison of the nearly stable activities obtained after ca. 20$60 \mathrm{~h}$ on stream of the various catalysts (Figure S9).

Figure $2 \mathrm{a}$ shows the ethylene conversion rates normalized to the silver surface area on the basis of a spherical particle assumption using average sizes determined by HAADF-STEM. For particles between 20 and $50 \mathrm{~nm}$, the reaction rate did not vary strongly. Strikingly, above $50 \mathrm{~nm}$ the rate increased nearly linearly with the average particle size independent for all reaction conditions. The catalytic rates without $\mathrm{VC}$ obtained at 20 bar (conditions B) were about 2-3 times higher than the rates obtained at a total pressure of 1 bar (conditions $C$ ). Such an influence of the pressure can be ascribed to a higher oxygen coverage of the silver surface. ${ }^{19,20}$ Figure $2 \mathrm{~b}$ shows that the EO selectivity was also higher at higher reaction pressure. In the presence of VC (conditions A), the oxidation reaction was strongly suppressed by competitive adsorption of chlorine. ${ }^{21,22}$
Figure 3 shows the strong dependence of EO selectivity on ethylene conversion. Under conditions A, the highest EO selectivity was obtained. The EO selectivities under conditions C were substantially lower $(\sim 40-50 \%)$ than those under conditions $\mathrm{A}$ and $\mathrm{B}$. We can estimate the intrinsic $\mathrm{EO}$ selectivity by extrapolating to zero ethylene conversion. The intrinsic EO selectivity was lower for conditions B (20 bar without $\mathrm{VC}$ ) than for conditions A (20 bar with $\mathrm{VC}$ ), which is in keeping with the promoting effect of chlorine associated with a higher amount of electrophilic oxygen species. ${ }^{21}$ It is also observed that, in the presence of chlorine, smaller particles exhibited a slightly lower EO selectivity in comparison to catalysts containing larger particles. The decrease in EO selectivity with increasing ethylene conversion is likely due to consecutive reactions of the primary EO product. EO can isomerize on hydroxyl groups of the support to acetaldehyde, which is prone to rapid combustion on the silver surface. Differences in EO selectivity may therefore also be due to the amount of support surface exposed, which depends among other things on the silver loading. The higher silver loading used to obtain catalysts with larger silver particles can thus explain the higher EO selectivity as well as the less pronounced decrease in the EO selectivity with increasing ethylene conversion. These trends are in keeping with earlier reports. ${ }^{9,10,23}$ In summary, larger silver particles gave rise to a higher (surface-normalized) activity and EO selectivity, especially in the presence of chlorine (conditions A).

The influence of the size of silver particles on the ethylene oxidation rate is unexpected. In general, it is expected that large silver particles with an fcc structure expose the most stable $\operatorname{Ag}(111)$ surface. Thus, it is not likely that the observed particle size effect is due to the appearance of specific surface topologies on larger particles with higher reactivity. On the other hand, the presence of oxygen at the surface can lead to the stabilization of other facets and also surface reconstruction should be considered. AAlthough the literature is not conclusive on this aspect, $\operatorname{Ag}(111)$, oxygen-induced reconstructed $\mathrm{Ag}(110)$, and $\mathrm{Ag}(100)$ surfaces have been considered in the context of ethylene epoxidation in addition to the $\operatorname{Ag}(111)$ surface. $^{24-26}$ None of these surfaces are completely 
oxidized under the reaction conditions according to theoretical works. $^{27,28}$

Figure 4 shows that the oxidation rate normalized to the total silver content (weight-based rate) is independent of size

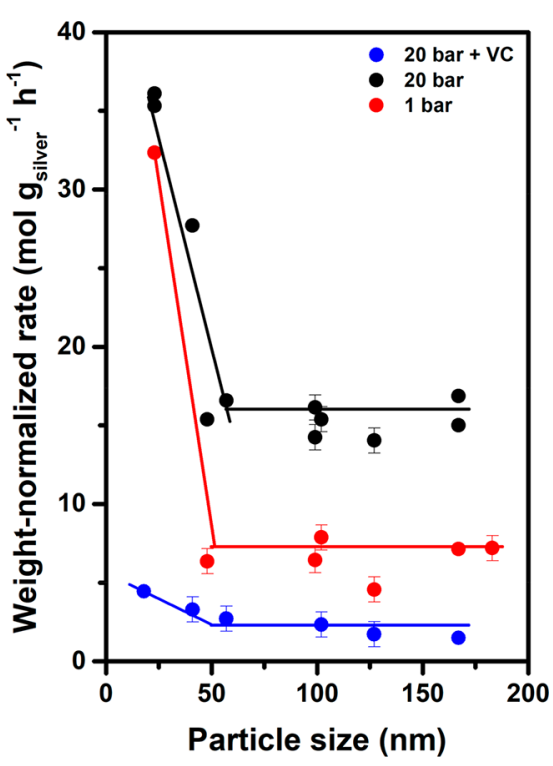

Figure 4. Weight-normalized reaction rate as a function of silver particle size (reaction conditions: $225^{\circ} \mathrm{C}, 5 \% \mathrm{C}_{2} \mathrm{H}_{4}, 10 \% \mathrm{O}_{2}$, further conditions in the figure). Error bars are based on the standard deviation, which is calculated from three repetitive experiments to determine the experimental error. Lines are added to guide the eye.

for particles larger than $50 \mathrm{~nm}$. This trend holds for all three reaction conditions, which implies that the reaction rate does not scale with the surface area of the silver particles. Instead, a bulk effect appears to affect the ethylene oxidation rate. We used the Scherrer equation to estimate the average crystallite size of the silver particles on the basis of the fwhm of the $\operatorname{Ag}(220)$ reflection. Table 1 shows that, except for the samples containing on average 19 and $23 \mathrm{~nm}$ particles, the silver particles are composed of ca. 25-30 nm silver crystallites, irrespective of the particle size. The silver crystallite size of $\operatorname{Ag}(19)$ and $\operatorname{Ag}(23)$ is slightly smaller. Thus, silver particles with a size larger than $\sim 50 \mathrm{~nm}$ have a domain structure, which means that they are polycrystalline. This aspect of supported silver particles in EO catalysts has already been mentioned in the work of Goncharova et al. $^{7}$ They argued that the increase in the activity observed for larger silver particles is due to a higher concentration of active sites at the vicinity of the grain boundaries. Grain boundaries can be effective channels for oxygen diffusion. ${ }^{29-31}$ Our data show that monocrystalline silver particles with a size up to $\sim 30 \mathrm{~nm}$ show a changing reaction rate per gram of silver. Above this size, the particles become polycrystalline and the reaction rate normalized to the silver weight remains constant. These data provide a strong indication that grain boundaries in the silver particles play an important role in ethylene oxidation.

A first possible explanation involves low oxygen coverage on the silver surface under the reaction conditions. In general, oxygen adsorbs very weakly on silver. For example, recent microkinetic modeling emphasized a very low oxygen coverage on the most stable $\operatorname{Ag}(111)$ surface under the reaction conditions. $^{25}$ Thus, other sites may be involved in the activation of molecular oxygen, such as defect sites close to the grain boundaries at the external surface, which can lead to the uptake of oxygen atoms between silver crystallites. These oxygen atoms can then dissolve in and diffuse through the bulk of the silver phase and appear at the external surface of the silver particles, where they are involved in ethylene epoxidation. If the rate of oxygen dissolution in the bulk of the primary crystallites is a slow step, the reaction rate will be proportional to the total surface area based on the silver crystallites (or rather the first shell of crystallites exposed to the external surface of the particles, vide infra). As particles larger than $50 \mathrm{~nm}$ are polycrystalline and composed of roughly similar-sized crystallites independent of the silver particle size, the total crystallite surface area will be independent of the silver particle size. In contrast, a strong effect of particle size is noted when the silver particles are smaller than $50 \mathrm{~nm}$. The silver particles in this range are monocrystalline, and the surface available for oxygen uptake increases with decreasing particle size, which can explain the higher ethylene oxidation rate. Temperature-programmed desorption of oxygen $\left(\mathrm{O}_{2}\right.$ TPD) was carried out for two silver catalysts (Figure S7): $\mathrm{Ag}(23)$ containing predominantly monocrystalline silver particles and $\operatorname{Ag}(127)$ consisting of multiple crystallites $(\sim 75) . \mathrm{O}_{2}$-TPD measurements were performed after exposure to oxygen at $250{ }^{\circ} \mathrm{C}$ for $3 \mathrm{~h}$ followed by cooling in oxygen to $50{ }^{\circ} \mathrm{C}$ and flushing in helium (Table S2). The oxygen content normalized to the external surface area of the silver particles amounted to 1.3 and 4.6 ML ( $\mathrm{ML}=$ monolayer), respectively, for $\operatorname{Ag}(23)$ and $\operatorname{Ag}(127)$. When they were normalized on the basis of the surface area of the crystallites, the oxygen contents for $\operatorname{Ag}(23)$ and $\operatorname{Ag}(127)$ were 1.1 and $1.0 \mathrm{ML}$ of $\mathrm{Ag}_{2} \mathrm{O}$, respectively. This result shows that the silver particles can take up a substantial amount of oxygen at the surface of the silver crystallites. While $\operatorname{Ag}(23)$ will predominantly contain oxygen adsorbed at the external surface, $\operatorname{Ag}(127)$ contains more dissolved oxygen. These results suggest that the external surface of the silver particles is covered with abundant oxygen after cooling in oxygen. We cannot directly relate these oxygen coverages to the ethylene oxidation reaction, because the coverages were determined after cooling in oxygen. Moreover, during ethylene oxidation oxygen species will be removed by reaction with ethylene.

We also considered an alternative explanation involving partial coverage of the silver surface by oxygen under reaction conditions. We consider again the microkinetic modeling work of Hus and Hellman: for instance, $\operatorname{Ag}(100)$ will contain $\sim 0.25$ ML of oxygen under ethylene oxidation conditions. ${ }^{25}$ To explain the role of a pathway involving oxygen adsorption via grain boundaries, we consider that the migration of oxygen from the external surface to the subsurface is limiting the overall reaction. Then, a supply of oxygen via grain boundary absorption and diffusion through the bulk to the external surface can play a role. This model implies that the nucleophilic oxygen species represented by atomic oxygen adsorbates on a metallic surface cannot react with ethylene. Only in the presence of subsurface oxygen when these oxygen atoms become more electrophilic is a pathway to ethylene oxidation opened. However, many works have emphasized that both nucleophilic and electrophilic oxygen species can oxidize ethylene. ${ }^{19,21,32,33}$ Moreover, single crystals of silver (presumably without grain boundaries) can also be active for silver epoxidation in the presence of oxygen. ${ }^{34-37}$ Accordingly, we conclude that the first explanation involving a low oxygen surface coverage is more likely than the second. 

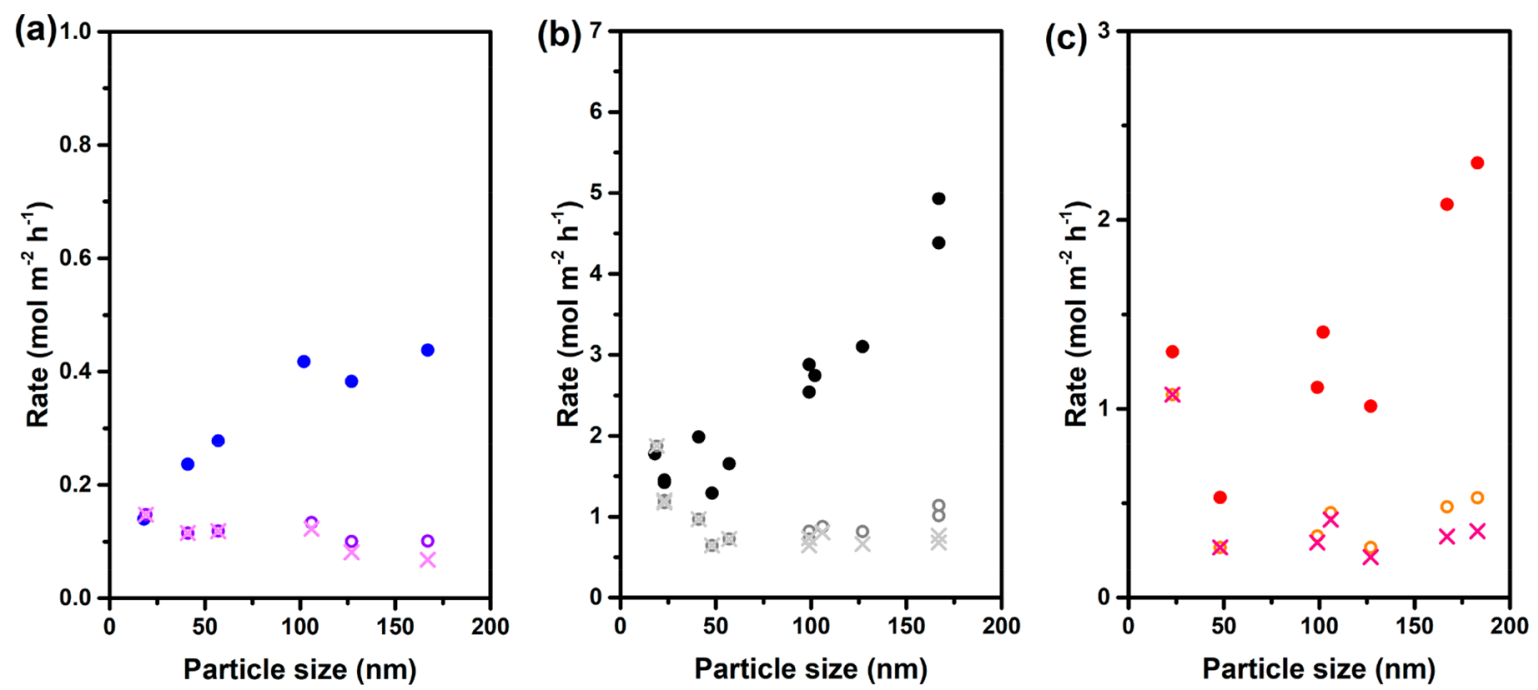

Figure 5. Ethylene oxidation rate normalized to the external surface of the silver particles (solid circles), the surface area of the first shell of crystallites that make up the silver particles (open circles), and the surface area of all crystallites that make up the silver particles (crosses): (a) 20 bar + VC; (b) 20 bar; (c) 1 bar (reaction conditions: $225{ }^{\circ} \mathrm{C}, 5 \% \mathrm{C}_{2} \mathrm{H}_{4}, 10 \% \mathrm{O}_{2}$ ).

Importantly, our data indicate that oxygen species diffusing through the bulk of the silver crystallites play a role in the ethylene oxidation reaction. The silver-oxygen bulk system has been well studied. $\mathrm{Ag}_{2} \mathrm{O}$ dissociates into solid $\mathrm{Ag}$ and $\mathrm{O}_{2}$ at temperatures above $189^{\circ} \mathrm{C}$ under atmospheric pressure. ${ }^{38}$ For solid bulk silver at $225{ }^{\circ} \mathrm{C}$, we estimate a maximum oxygen content of $\sim 20 \mathrm{ppm}$ at an oxygen partial pressure of 2 bar (conditions $\mathrm{B}$ ) and $\sim 6 \mathrm{ppm}$ at an oxygen partial pressure of 0.2 bar (conditions C). ${ }^{39}$ Thus, it is most likely that under the reaction conditions only small amounts of oxygen are present in the bulk. ${ }^{40-42}$ At the external surface of the particles, these oxygen atoms can be involved in ethylene oxidation. Our catalytic rate data show that an increase of the pressure from 1 to 20 bar leads to a 3 -fold increase in the oxidation rate, which is in reasonable agreement with the estimated increase in the oxygen content of bulk silver under these conditions. A higher amount of dissolved oxygen in the bulk will increase the oxygen coverage at the external surface of the silver particles.

Thus, the observed trends can be explained by a limited availability of oxygen atoms at the external surface. This is because oxygen adsorption on the external surface is slow. It would lead to a strong decrease in ethylene oxidation rate with increasing particle size. This decrease is observed for monocrystalline particles smaller than $50 \mathrm{~nm}$. However, for larger particles an additional faster oxygen supply pathway to the surface is opened, which involves oxygen dissociation at particular defect sites close to grain boundaries followed by uptake at grain boundaries and bulk diffusion to the surface. Previously established kinetic models seem to suggest that oxygen adsorption is a kinetically relevant step. ${ }^{4344}$ Furthermore, under close to industrial conditions the ethylene conversion rate has a strong positive order in oxygen and is close to zero in ethylene pressure. ${ }^{43,45,46}$ On the basis of the observation that the maximum oxygen content is proportional to the crystallite surface area, we propose that oxygen activation occurs at specific defect sites at the surface followed by diffusion along the grain boundaries, uptake in the bulk, and diffusion to the external surface. In contrast, ethylene can only access the external surface area of the silver particle.

Obviously, a model in which oxygen diffusion from grain boundaries through the bulk to the external surface of silver particles accounts for ethylene oxidation would only involve crystallites that are partially exposed to the gas phase. Accordingly, we used a simple geometrical model in which we divided spherical silver particles (average particle size from HAADF-STEM) in uniformly sized spherical crystallites (crystallite size based on XRD). The details of the calculations are given in section S7 in the Supporting Information. The ethylene oxidation rate normalized to the surface area of these crystallites is nearly independent of the silver particle size for particles larger than $50 \mathrm{~nm}$, in both the absence and presence of chlorine (Figure 5). It should be noted that, in this particle size range, this correlation is similar when the rate is based on the surface area of all crystallites in a silver particle. The reaction rates normalized to crystallite surface obtained for particles larger than $50 \mathrm{~nm}$ are about $0.2-0.4 \mathrm{~mol} \mathrm{~m}^{-2} \mathrm{~h}^{-1}$ under conditions $\mathrm{C}$. These rates are close to the ethylene conversion rates observed for single-crystal studies under comparable conditions (Table S2).

Thus, our model can well explain the unusual structure sensitivity for the ethylene oxidation reaction. As the reaction rate is likely controlled by the grain boundaries of external crystallites, one expects a decrease in the reaction rate for very large particles. To verify a possible upper limit, we evaluated the catalytic performance of a silver powder under conditions B. The silver powder had a particle size of $\sim 3.5 \mu \mathrm{m}$ and a primary crystallite size of $\sim 50 \mathrm{~nm}$ according to XRD. The surface-normalized rate is approximately $6 \mathrm{~mol} \mathrm{~m}^{-2} \mathrm{~h}^{-1}$, whichis substantially lower than expected on the basis of the linear correlation for conditions B in Figure 2, even when the larger primary crystallite size is considered. This suggests that there is an optimum particle size for these silver particles, which also depends on the primary crystallite size. We expect that this will also depend on the preparation and activation method. We attempted to increase the crystallite size of our catalysts in a variety of manners, however without success. Even sintering of $\mathrm{Ag}(167)$ at $800{ }^{\circ} \mathrm{C}$ in hydrogen to an average particle size of $\sim 250 \mathrm{~nm}$ resulted in a nearly similar primary crystallite size of $31 \mathrm{~nm}$ as determined by XRD. The catalytic performance of this sample was not evaluated.

As mentioned earlier, there is a substantial difference in time on stream behavior between various particle sizes. Figure 6 


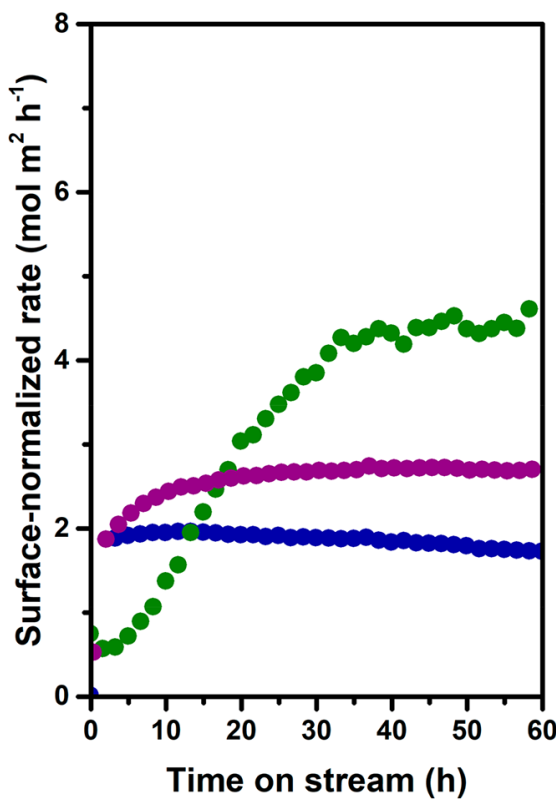

Figure 6. Surface area normalized reaction rate as a function of time on stream for $\operatorname{Ag}(41)$ (blue solid circles), $\operatorname{Ag}(106)$ (purple solid circles), and $\operatorname{Ag}(167)$ (green solid circles) (reaction conditions: 20 bar, $\left.225{ }^{\circ} \mathrm{C}, 5 \% \mathrm{C}_{2} \mathrm{H}_{4}, 10 \% \mathrm{O}_{2}\right)$.

shows time on stream data for $\operatorname{Ag}(41), \operatorname{Ag}(99)$, and $\operatorname{Ag}(167)$ catalyst samples for conditions B (additional data are given in Figure S9 in the Supporting Information). Small particles $(<50$ $\mathrm{nm}$ ) exhibit typically a fast activation behavior, and the ethylene conversion becomes stable within a few hours. For larger particles, the time to reach a stable rate becomes longer: i.e., $30 \mathrm{~h}$ for $\operatorname{Ag}(99)$ and $\sim 50 \mathrm{~h}$ for $\operatorname{Ag}(167)$. The same trend is observed for the experiments at 1 bar (conditions C, Figure S9 in the Supporting Information). In contrast, the activity is nearly constant for experiments done with $\mathrm{VC}$ in the feed (conditions A). Only for $\mathrm{Ag}(167)$ is a slight increase of the activity over time noted. It is likely that the activation behavior in the catalytic activity measurements in the presence of $\mathrm{VC}$ is obscured by chlorine inhibition of the silver surface.

An increasing activation period for larger particles strongly suggests that not only the external surface needs to be activated but also the bulk is involved in this transition. Within our proposed model, oxygen uptake from the crystallite external surface into the bulk may be a slow step in the overall mechanism. Then, the transient behavior can be due to the buildup of atomic oxygen along the grain boundaries. For relatively small particles, the surface to bulk ratio is high and grain boundaries play a minor role. Activation for large particles takes longer, because of a slower buildup of a sufficient oxygen concentration at the grain boundaries. Another relevant aspect in this regard is mentioned in the work of Schlögl, who showed that in the context of methanol oxidation the diffusion of oxygen in the bulk of silver is an autocatalytic process involving a lattice expansion which facilitates oxygen diffusion. ${ }^{29}$ This might also explain the increase in reactivity at higher partial pressures of oxygen. As observed in an earlier contribution by our group and in this work (Figure S6 in the Supporting Information), the silver particles significantly restructure under the influence of the epoxidation reaction. ${ }^{47}$

An important corollary of the present data is that there is only a small influence of the particle size on the total rate expressed per weight of silver for typical particle sizes. As the grain boundaries play a role in accommodating atomic oxygen species relevant to ethylene oxidation at the external surface of silver particles, we do not expect a significant influence of sintering of the silver phase as long as the primary crystallite size remains the same. We determined the silver particle size and the crystallite size of used silver catalysts. The corresponding data are given in Table 2 . In line with our earlier work, we observe that larger silver particles sinter during the ethylene oxidation reaction in the absence of chlorine, while the particle size changed to a much smaller degree in the presence of chlorine. ${ }^{47}$ Most importantly, the crystallite size of the silver particles did not change significantly. Additionally, we also established by in situ XRD that the crystallite size did not vary after prolonged exposure $(60 \mathrm{~h})$ under a pressure of 5 bar of $\mathrm{O}_{2}$ at $225^{\circ} \mathrm{C}$ (Figure S10). The particle size growth for the chlorine-free experiments did not lead to a decrease in the reaction rate. These findings are in accord with our hypothesis that the total reaction rate is not directly affected by the silver particle size but rather by silver crystallite size. The deactivation observed during prolonged reaction under industrial conditions may for instance be due to a slow growth of the primary crystallites. ${ }^{48}$

Taken together, our findings provide new insight into the structure sensitivity of silver particles for ethylene oxidation. Small monocrystalline silver particles show a usual decreasing weight-based activity with particle size. Particles larger than 50 $\mathrm{nm}$, however, are polycrystalline and their weight-based rate does not decrease further with particle size. We found strong indications that an additional pathway for oxygen activation exists in which grain boundaries between the primary crystallites of the silver particles are involved. We propose a mechanism involving oxygen activation at specific sites at the external surface, diffusion of atomic oxygen along grain boundaries, and, as a slow step, diffusion of oxygen atoms into the bulk of silver and reappearance at the external surface where the oxidation reaction takes place. As demonstrated before, ${ }^{19,20,49} \mathrm{EO}$ selectivity strongly depends on the nature of the oxygen species at the surface. A higher EO selectivity is obtained at higher oxygen pressure, which can be linked to a higher oxygen surface coverage. The presence of chlorine can further increase the EO selectivity, likely through modification of the electrophilicity of adsorbed oxygen species. ${ }^{16,21,50} \mathrm{We}$

Table 2. Particle and Crystallite Sizes for Fresh and Used $(60 \mathrm{~h})$ Silver Catalysts

\begin{tabular}{|c|c|c|c|c|c|c|}
\hline \multirow[b]{2}{*}{ sample } & \multicolumn{2}{|c|}{ fresh } & \multicolumn{2}{|c|}{ used 20 bar (conditions B) } & \multicolumn{2}{|c|}{ used $20 \mathrm{bar}+\mathrm{VC}$ (conditions A) } \\
\hline & particle size $(\mathrm{nm})^{a}$ & crystallite size $(\mathrm{nm})^{b}$ & particle size $(\mathrm{nm})^{a}$ & crystallite size $(\mathrm{nm})^{b}$ & particle size $(\mathrm{nm})^{a}$ & crystallite size $(\mathrm{nm})^{b}$ \\
\hline $\operatorname{Ag}(41)$ & 41 & 20 & 45 & 21 & 57 & 26 \\
\hline $\operatorname{Ag}(106)$ & 106 & 30 & 175 & 24 & 93 & 32 \\
\hline $\operatorname{Ag}(167)$ & 167 & 26 & 211 & 24 & 182 & 27 \\
\hline
\end{tabular}

${ }^{a}$ Average particle size determined by HAADF-STEM. ${ }^{b}$ Crystallite size determined by XRD. 
observe that the EO selectivity decreases with increasing ethylene conversion, which is most likely due to consecutive reactions of EO on support hydroxyl sites. The way EO selectivity changes with ethylene conversion depends on the coverage of the support by silver. As a consequence, a catalyst containing larger silver particles obtained by using a higher silver loading shows a higher EO selectivity in the presence of chlorine as well as a less pronounced decrease of EO selectivity with increasing ethylene conversion in comparison with catalysts with smaller particles (lower silver loading). The important role of grain boundaries noted in this work has already been mentioned by Goncharova et al., although their explanation is different from ours. Schlögl and co-workers also emphasized the role of oxygen diffusion along grain boundaries in the context of silver-catalyzed oxidation of methanol to formaldehyde, which is carried out at much higher temperature. $^{30}$

Finally, it is useful to revisit some of the older studies on the influence of particle size. Verykios et al. observed the lowest surface specific reaction rate for silver particles with a size of 70-80 nm. These particles had a relatively large primary crystallite size among the samples measured. In another paper by $\mathrm{Lu}$ et al., a linear increase in the activity with particle size (up to $600 \mathrm{~nm}$ ) was reported, similar to our work. ${ }^{51}$ The primary crystallite size of these particles was reported to be constant at $13 \mathrm{~nm}$. In the work of Lee et al., single-crystalline particles in the range of 20-100 nm were evaluated for ethylene oxidation and the highest activity was found for 60 nm silver particles. ${ }^{10}$

These insights lead to the following important statements with respect to structure sensitivity for silver-catalyzed ethylene epoxidation. The typical silver particles used for ethylene oxidation are larger than $10 \mathrm{~nm}$ and, beyond a certain size $(\sim 30 \mathrm{~nm})$, consist of multiple silver crystallites. The total ethylene oxidation rate is not structure sensitive, as it correlates with the total primary crystallite surface involved in the dissolution of oxygen atoms into bulk silver. It is reasonable to assume that only the outer shell of crystallites in the silver particle contributes to the surface catalysis. As there are hardly systematic studies of the effect of primary crystallize size on ethylene oxidation, we can only speculate that there will be a size beyond which the rate of oxygen diffusion through the bulk becomes limiting. The upper limit suggested by this was confirmed by the lower than expected rate for a silver powder consisting of relatively large particles. A higher oxygen partial pressure leads to a higher oxygen coverage, which benefits EO selectivity. ${ }^{20,49}$ Other factors influencing the EO selectivity are the presence of chlorine at the surface and the concentration of support acid sites.

\section{CONCLUSIONS}

In this work, we investigated the impact of particle size of the silver phase on the ethylene oxidation reaction. We prepared $\mathrm{Ag} / \alpha-\mathrm{Al}_{2} \mathrm{O}_{3}$ catalysts in which the average size of silver particles varied between 20 and $200 \mathrm{~nm}$. Small silver particles with a size up to $\sim 40 \mathrm{~nm}$ are monocrystalline, their reaction rate normalized to the external surface being independent of size. In contrast, particles larger than $50 \mathrm{~nm}$ are polycrystalline (average domain size in the $25-30 \mathrm{~nm}$ range) with surfacenormalized reaction rates increasing linearly with particle size. For these larger particles, the ethylene oxidation rate expressed per gram of silver remains nearly constant. We explain this unusual behavior by a specific role of the bulk of the particles and, in particular, the grain boundaries. We propose that oxygen does not dissociate on the external surface, except for some defect sites through which grain boundaries take up oxygen atoms. These oxygen atoms then slowly dissolve in bulk silver and diffuse to the external surface, where they react with ethylene. The reaction rate normalized to the surface area of the first outer shell of crystallites making up silver particles is independent of the size of polycrystalline particles. We link the higher rate observed at higher oxygen partial pressure to a higher oxygen content of bulk silver. This also benefits EO selectivity. Adding chlorine further improves the EO selectivity through modification of the active oxygen surface species. The same particle size dependences are observed at 1 bar and at 20 bar without and with chlorine added. The main finding of our work is that for large enough particles the ethylene oxidation rate normalized to the silver weight is independent of size. The origin lies in the difficulty in activating molecular oxygen at the external surface, requiring an alternative pathway involving grain boundaries and the bulk. We speculate that the preference for large silver particles in industrial catalysts stems from the high silver loadings used, leading to a high silver coverage of the $\alpha-\mathrm{Al}_{2} \mathrm{O}_{3}$ support decreasing undesired consecutive reactions of $\mathrm{EO}$ on its hydroxyl groups.

\section{ASSOCIATED CONTENT}

\section{S Supporting Information}

The Supporting Information is available free of charge on the ACS Publications website at DOI: 10.1021/acscatal.9b02720.

Additional characterization including XPS spectra, SEM analysis, particle size histograms, different normalizations of rates, $\mathrm{O}_{2}$-TPD profiles, in situ $\mathrm{XRD}$, and time on stream behavior (PDF)

\section{AUTHOR INFORMATION}

\section{Corresponding Author}

*E-mail for E.J.M.H.: e.j.m.hensen@tue.nl.

ORCID

A. J. F. van Hoof: 0000-0002-9649-031X

H. Friedrich: 0000-0003-4582-0064

E. J. M. Hensen: 0000-0002-9754-2417

Notes

The authors declare no competing financial interest.

\section{ACKNOWLEDGMENTS}

The authors thank the Impuls program of the Eindhoven University of Technology and a Top grant of The Netherlands Organization for Scientific Research (NWO) for funding. Adelheid Elemans-Mehring is acknowledged for performing ICP-OES.

\section{REFERENCES}

(1) TechNavio. Global Ethylene Oxide and Ethylene Glycol Market 2016-2020; TechNavio: London, United Kingdom, 2016.

(2) Rebsdat, S.; Mayer, D. Ethylene Oxide. In Ullmann's Encyclopedia of Industrial Chemistry; Wiley-VCH: 2000; pp 547-572.

(3) Honkala, K.; Hellman, A.; Remediakis, I. N.; Logadottir, A.; Carlsson, A.; Dahl, S.; Christensen, C. H.; Nørskov, J. K. Ammonia Synthesis from First-Principles Calculations. Science 2005, 307, 555558.

(4) den Breejen, J. P.; Radstake, P. B.; Bezemer, G. L.; Bitter, J. H.; Froseth, V.; Holmen, A.; de Jong, K. P. On the Origin of the Cobalt Particle Size Effects In. J. Am. Chem. Soc. 2009, 131, 7197-7203. 
(5) Bezemer, G. L.; Bitter, J. H.; Kuipers, H. P. C. E.; Oosterbeek, H.; Holewijn, J. E.; Xu, X.; Kapteijn, F.; van Dillen, A. J.; de Jong, K. P. Cobalt Particle Size Effects in the Fischer-Tropsch Reaction Studied with Carbon Nanofiber Supported Catalysts. J. Am. Chem. Soc. 2006, 128, 3956-3964.

(6) Ligthart, D. A. J. M.; van Santen, R. A.; Hensen, E. J. M. Influence of Particle Size on the Activity and Stability in Steam Methane Reforming of Supported Rh Nanoparticles. J. Catal. 2011, 280, 206-220.

(7) Goncharova, S. N.; Bal'zhinimaev, B. S.; Tsybulya, S. V.; Zaikovskii, V. I. Synthesis of Silver Supported Catalysts with Narrow Particle Size Distribution. Stud. Surf. Sci. Catal. 1995, 91, 915-922.

(8) Wu, J. C.; Harriott, P. The Effect of Crystallite Size on the Activity and Selectivity of Silver Catalysts. J. Catal. 1975, 39, 395402.

(9) Verykios, X. E.; Stein, F. P.; Coughlin, R. W.; Coughlin, R. W. Influence of Metal Crystallite Size and Morphology on Selectivity and Activity of Ethylene Oxidation Catalyzed by Supported Silver. J. Catal. 1980, 66, 368-382.

(10) Lee, J. K.; Verykios, X. E.; Pitchai, R. Support and Crystallite Size Effects in Ethylene Oxidation Catalysis. Appl. Catal. 1989, 50, 171-188.

(11) van den Reijen, J. E.; Kanungo, S.; Welling, T. A. J.; VersluijsHelder, M.; Nijhuis, T. A.; de Jong, K. P.; de Jongh, P. E. Preparation and Particle Size Effects of $\mathrm{Ag} / \alpha-\mathrm{Al}_{2} \mathrm{O}_{3}$ Catalysts for Ethylene Epoxidation. J. Catal. 2017, 356, 65-74.

(12) Sorokin, A. M.; Prosvirin, I. P.; Demidov, D. V.; Bukhtiyarov, V. I. Size Effect in Ethylene Oxidation over Silver Nanoparticles Supported on HOPG. Proceedings of the Internation Conference Nanomaterials: Applications and Properties; 2013, Vol. 2, pp 1-4.

(13) Goncharova, S. N.; Paukshtis, E. A.; Bal'zhinimaev, B. S. Size Effects in Ethylene Oxidation on Silver Catalysts. Influence of Support and Cs Promoter. Appl. Catal., A 1995, 126, 67-84.

(14) Tsybulya, S. V. Study of the Real Structure of Silver Supported Catalysts of Different Dispersity. J. Catal. 1995, 154, 194-200.

(15) Kemp, R. A.; Evans, W. E.; Matusz, M. Process for Preparing Ethylene Oxide Catalysts; Patent EP0716884A2, 1995.

(16) Atkins, M.; Couves, J.; Hague, M.; Sakakini, B. H.; Waugh, K. C. On the Role of $\mathrm{Cs}, \mathrm{Cl}$ and Subsurface O in Promoting Selectivity in $\mathrm{Ag} / \alpha-\mathrm{Al}_{2} \mathrm{O}_{3}$ Catalysed Oxidation of Ethene to Ethene Epoxide. J. Catal. 2005, 235, 103-113.

(17) Patterson, A. L. The Scherrer Formula for X-Ray Particle Size Determination. Phys. Rev. 1939, 56, 978-982.

(18) Evans, W. E.; Mesters, C. M. A. M. Ethylene Oxide Catalysts and Process; Patent US005703253A, 1997.

(19) Bukhtiyarov, V. I.; Nizovskii, A. I.; Bluhm, H.; Hävecker, M.; Kleimenov, E.; Knop-Gericke, A.; Schlögl, R. Combined in Situ XPS and PTRMS Study of Ethylene Epoxidation over Silver. J. Catal. 2006, $238,260-269$.

(20) Akella, L. M.; Lee, H. H. Selectivity Characterization of Ethylene Oxidation Reactions: Oxygen Chemisorption. J. Catal. 1984, $86,465-472$.

(21) Rocha, T. C. R.; Hävecker, M.; Knop-Gericke, A.; Schlögl, R. Promoters in Heterogeneous Catalysis: The Role of $\mathrm{Cl}$ on Ethylene Epoxidation over Ag. J. Catal. 2014, 312, 12-16.

(22) Harris, J. W.; Bhan, A. Moderation of Chlorine Coverage and Ethylene Epoxidation Kinetics via Ethane Oxychlorination over Promoted $\mathrm{Ag} / \alpha-\mathrm{Al}_{2} \mathrm{O}_{3}$. J. Catal. 2018, 367, 62-71.

(23) Christopher, P.; Linic, S. Shape- and Size-Specific Chemistry of Ag Nanostructures in Catalytic Ethylene Epoxidation. ChemCatChem 2010, 2, 78-83.

(24) Jones, T. E.; Wyrwich, R.; Bocklein, S.; Rocha, T. C. R.; Carbonio, E. A.; Knop-Gericke, A.; Schlögl, R.; Gunther, S.; Wintterlin, J.; Piccinin, S. Oxidation of Ethylene on Oxygen Reconstructed Silver Surfaces. J. Phys. Chem. C 2016, 120, 2863028638.

(25) Huš, M.; Hellman, A. Ethylene Epoxidation on $\mathrm{Ag}(100)$, $\operatorname{Ag}(110)$, and $\operatorname{Ag}(111): A$ Joint $\mathrm{Ab}$ Initio and Kinetic Monte Carlo
Study and Comparison with Experiments. ACS Catal. 2019, 9, 11831196.

(26) Yang, L.; Rahman, T. S.; Bracco, G.; Tatarek, R. Missing-Row Reconstruction of $\operatorname{Ag}(110)$ Induced by a @p $(2 \times 1)$ Oxygen Overlayer. Phys. Rev. B: Condens. Matter Mater. Phys. 1989, 40, 12271-12279.

(27) Michaelides, A.; Reuter, K.; Scheffler, M. When Seeing Is Not Believing: Oxygen on $\operatorname{Ag}(111)$, a Simple Adsorption System? J. Vac. Sci. Technol., A 2005, 23, 1487-1497.

(28) Martin, N. M.; Klacar, S.; Grönbeck, H.; Knudsen, J.; Schnadt, J.; Blomberg, S.; Gustafson, J.; Lundgren, E. High-Coverage OxygenInduced Surface Structures on $\operatorname{Ag}(111)$. J. Phys. Chem. C 2014, 118, 15324-15331.

(29) Nagy, A. J.; Mestl, G.; Herein, D.; Weinberg, G.; Kitzelmann, E.; Schlögl, R. The Correlation of Subsurface Oxygen Diffusion with Variations of Silver Morphology in the Silver-Oxygen System. J. Catal. 1999, 182, 417-429.

(30) Nagy, A.; Mestl, G.; Rühle, T.; Weinberg, G.; Schlögl, R. The Dynamic Restructuring of Electrolytic Silver during the Formaldehyde Synthesis Reaction. J. Catal. 1998, 179, 548-559.

(31) Outlaw, R. A.; Sankaran, S. N.; Hoflund, G. B.; Davidson, M. R. Oxygen Transport through High-Purity, Large-Grain Ag. J. Mater. Res. 1988, 3, 1378-1384.

(32) Jones, T. E.; Rocha, T. C. R.; Knop-Gericke, A.; Stampfl, C.; Schlögl, R.; Piccinin, S. Insights into the Electronic Structure of the Oxygen Species Active in Alkene Epoxidation on Silver. ACS Catal. 2015, 5, 5846-5850.

(33) Bukhtiyarov, V. I.; Hävecker, M.; Kaichev, V. V.; Knop-Gericke, A.; Mayer, R. W.; Schlögl, R. X-Ray Absorption and Photoemission Studies of the Active Oxygen for Ethylene Epoxidation over Silver. Catal. Lett. 2001, 74, 121-125.

(34) Grant, R. B.; Lambert, R. M. A Single Crystal Study of the Silver-Catalysed Selective Oxidation and Total Oxidation of Ethylene. J. Catal. 1985, 92, 364-375.

(35) van Santen, R. A.; Groot, D. E. The Mechanism of Ethylene Epoxidation. J. Catal. 1986, 98, 530-539.

(36) Campbell, C. T. The Selective Epoxidation of Ethylene Catalyzed by $\operatorname{Ag}(111)$ : A Comparison with $\operatorname{Ag}(110)$. J. Catal. 1985, 94, 436-444.

(37) Campbell, C. T.; Koel, B. E. Chlorine Promotion of Selective Ethylene Oxidation over $\mathrm{Ag}(110)$ : Kinetics and Mechanism. J. Catal. 1985, 92, 272-283.

(38) Karakaya, I.; Thompson, W. T. The Ag-O (Silver-Oxygen) System. J. Phase Equilib. 1992, 13, 137-142.

(39) Baird, J. K.; King, T. R.; Stein, C. Diffusion of Oxygen in Silver. J. Phys. Chem. Solids 1999, 60, 891-894.

(40) Firet, N. J.; Blommaert, M. A.; Burdyny, T.; Venugopal, A.; Bohra, D.; Longo, A.; Smith, W. A. Operando EXAFS Study Reveals Presence of Oxygen in Oxide-Derived Silver Catalysts for Electrochemical $\mathrm{CO}_{2}$ Reduction. J. Mater. Chem. A 2019, 7, 2597-2607.

(41) Bukhtiyarov, V.; Boronin, A.; Prosvirin, I.; Savchenko, V. Stages in the Modification of a Silver Surface for Catalysis of the Partial Oxidation of Ethylene I. Action of Oxygen. J. Catal. 1994, 150, 262267.

(42) Waterhouse, G. I. N.; Bowmaker, G. A.; Metson, J. B. Oxygen Chemisorption on an Electrolytic Silver Catalyst: A Combined TPD and Raman Spectroscopic Study. Appl. Surf. Sci. 2003, 214, 36-51.

(43) Stegelmann, C.; Schiødt, N. C.; Campbell, C. T.; Stoltze, P. Microkinetic Modeling of Ethylene Oxidation over Silver. J. Catal. 2004, 221, 630-649.

(44) Linic, S.; Barteau, M. A. Construction of a Reaction Coordinate and a Microkinetic Model for Ethylene Epoxidation on Silver from DFT Calculations and Surface Science Experiments. J. Catal. 2003, 214, 200-212.

(45) Force, E. L.; Bell, A. T. The Relationship of Adsorbed Species Observed by Infrared Spectroscopy to the Mechanism of Ethylene Oxidation over Silver. J. Catal. 1975, 40, 356-371.

(46) Chen, C. J.; Harris, J. W.; Bhan, A. Kinetics of Ethylene Epoxidation on a Promoted $\mathrm{Ag} / \alpha-\mathrm{Al}_{2} \mathrm{O}_{3}$ Catalyst-The Effects of 
Product and Chloride Co-Feeds on Rates and Selectivity. Chem. - Eur. J. 2018, 24, 12405-12415.

(47) van Hoof, A. J. F.; Filot, I. A. W.; Friedrich, H.; Hensen, E. J. M. Reversible Restructuring of Silver Particles during Ethylene Epoxidation. ACS Catal. 2018, 8, 11794-11800.

(48) Zhou, X. G.; Yuan, W. K. Modeling Silver Catalyst Sintering and Epoxidation Selectivity Evolution in Ethylene Oxidation. Chem. Eng. Sci. 2004, 59, 1723-1731.

(49) Williams, F. J.; Bird, D. P. C.; Palermo, A.; Santra, A. K.; Lambert, R. M. Mechanism, Selectivity Promotion, and New Ultraselective Pathways in Ag-Catalyzed Heterogeneous Epoxidation. J. Am. Chem. Soc. 2004, 126, 8509-8514.

(50) Özbek, M. O.; Önal, I.; Van Santen, R. A. Ethylene Epoxidation Catalyzed by Chlorine-Promoted Silver Oxide. J. Phys.: Condens. Matter 2011, 23, 404202.

(51) Lu, J.; Bravosuarez, J.; Takahashi, A.; Haruta, M.; Oyama, S. T. In Situ UV-Vis Studies of the Effect of Particle Size on the Epoxidation of Ethylene and Propylene on Supported Silver Catalysts with Molecular Oxygen. J. Catal. 2005, 232, 85-95. 